\title{
Heightened Cocaine and Food Self-Administration in Female Rats with Neonatal Isolation Experience
}

\author{
Therese A Kosten*,', Xiang Yang Zhang' and Priscilla Kehoe ${ }^{2}$ \\ 'Division of Substance Abuse, Yale University School of Medicine, VA-CT Hospital System, West Haven, CT, USA; ${ }^{2}$ School of Biological Sciences, \\ University of California Irvine, CA, USA
}

\begin{abstract}
Previously, we demonstrated that the early life stress of neonatal isolation facilitates acquisition of cocaine and food self-administration in adult female rats. We now test whether it enhances responding for these reinforcers after operant performance is established. Adult female rats were derived from litters that were either subjected to neonatal isolation (I h/day isolation; postnatal days 2-9) or were nonhandled and assigned to one of two experiments. In Experiment I, female rats well trained to self-administer cocaine were tested under a fixed-ratio 3 (FR3) schedule with several cocaine doses $(0.0625-1.0 \mathrm{mg} / \mathrm{kg} /$ infusion) and under a progressive-ratio (PR) schedule $(0,0.5$, and $1.0 \mathrm{mg} / \mathrm{kg} /$ infusion cocaine). In Experiment 2, female rats well trained to respond for food reinforcers under an FR I 5 schedule were tested under two PR schedules. Results show that neonatal isolation enhanced responding for cocaine under both schedules of reinforcement and increased responding for food under a PR schedule of reinforcement. These data extend our previous acquisition study in female rats to show that neonatal isolation enhances responding under maintenance conditions. These enduring behavioral changes may relate to the ability of neonatal isolation to increase striatal dopamine responses to psychostimulants, effects we showed previously in infant and juvenile rats.

Neuropsychopharmacology (2006) 3 I, 70-76. doi: I0. I038/sj.npp. I 300779; published online I June 2005
\end{abstract}

Keywords: maternal separation; stress; sex differences; operant behavior; progressive ratio

\section{INTRODUCTION}

Stress is associated with increased initiation and maintenance of drug addiction (Rhoads, 1983; Kosten et al, 1986; Wilsnack et al, 1997; Najavits et al, 1998). Although a majority of cocaine addicts are male, female addicts are more likely than males to have comorbid post-traumatic stress disorder (Najavits et al, 1998) or a history of child abuse (Wechsberg et al, 1998). In rats, stress increases the ability of psychoactive drugs to enhance locomotor activity (Herman et al, 1984; Leyton and Stewart, 1990; Deroche et al, 1995; Haile et al, 2001), support place conditioning (Bell et al, 1997; Will et al, 1998; Haile et al, 2001), and promote acquisition of self-administration behavior (Piazza et al, 1990; Deminiere et al, 1992; Haney et al, 1995; Tidey and Miczek, 1997; Kosten et al, 2000). A few studies have examined the effects of stress on drug self-administration

\footnotetext{
*Correspondence: Dr TA Kosten, Division of Substance Abuse, Yale University School of Medicine, VA-CT Hospital System, 950 Campbell Avenue, Building 5, 3rd Floor, West Haven, CT 06516, USA, Tel: + | 203932 57| | ×5 100, Fax: + | 203937 4915,

E-mail: therese.kosten@yale.edu

Received I November 2004; revised 8 February 2005; accepted 13 April 2005

Online publication: 21 April 2005 at http://www.acnp.org/citations/ NPP042 105040508/default.pdf
}

after behavior is well established (ie maintenance conditions), and report enhanced responding after stress (Shaham and Stewart, 1994; Zhang et al, 2005). Much of the research in rats utilized male rats. However, Haney et al (1995) employed rats of both genders and reports no gender differences in the ability of social stress to enhance acquisition of drug self-administration. Because there are many neural, hormonal, and behavioral effects that are greater in female rats, in particular stress and drug responses (Becker, 1999; Rivier, 1999), it is likely that stress will enhance cocaine self-administration in female rats.

Common hormonal and neural effects of stress and psychoactive drugs may underlie the ability of stress to facilitate the behavioral effects of cocaine. Both stress and psychostimulants activate the hypothalamic-pituitaryadrenal (HPA) axis (Knich and Eisenberg, 1979; Moldow and Fischman, 1987; Rivier and Vale, 1987) and dopamine (DA) neurotransmission in limbic regions (Fadda et al, 1978; Deutch and Roth, 1990; Sorg and Kalivas, 1991; Imperato et al, 1992; Hamamura and Fibiger, 1993). Further, stress and cocaine lead to common intracellular adaptations within the mesolimbic DA system (Saal et al, 2003). The mesolimbic DA system contributes to the behavioral effects of cocaine including its ability to act as a reinforcer (Ritz et al, 1987; Koob and Bloom, 1988; Bergman et al, 1989). 
Our research demonstrates that the early life stress of neonatal isolation (ISO; individual pup isolation for $1 \mathrm{~h} /$ day on postnatal days 2-9 (PN2-9)) increases ventral striatal DA responses to psychostimulant administration in infant and juvenile rats (Kehoe et al, 1996, 1998a; Kosten et al, 2003). Consistent with these neurochemical effects, we show that female ISO rats exhibit enhanced acquisition of cocaine selfadministration relative to nonhandled $(\mathrm{NH})$ control rats in adulthood (Kosten et al, 2004). We also find that ISO enhances acquisition of operant responding for food in adult female rats, suggesting that ISO had a more generalized effect on operant performance rather than a specific effect on sensitivity to cocaine. The purpose of this study is to test whether ISO enhances responding for cocaine and food in female rats after behavior is well established. Tests were conducted using both fixed-ratio (FR) and progressive-ratio $(\mathrm{PR})$ schedules with several cocaine doses and with food.

\section{MATERIALS AND METHODS}

\section{General Methods}

Subjects and housing. Female rats were derived from several litters born to Sprague-Dawley rats. Litters were born on a day designated PN0 and culled to 12 pups, six males, and six females whenever possible, on PN1. Only female rats were employed in the present studies; male rats from these litters were used in separate studies. The neonatal isolation procedure was as described previously (Kosten et al, 2004). Briefly, beginning on PN2, all pups in an isolate litter were weighed and each pup was placed in an individual plastic container with no bedding. Each pup was isolated for $1 \mathrm{~h}$ /day until PN9 in a heated $\left(30^{\circ}\right)$ chamber with white noise to mask other pups' calls. $\mathrm{NH}$ control rats were derived from litters born about the same time. These litters were also culled to 12 pups on PN1, but were not handled nor disturbed during PN2-9 including for cage cleaning. After birth, rats were housed with their siblings and dam in polypropylene cages in a temperature- and humidity-controlled colony room maintained on a 12:12 light/dark cycle (lights on at 0700) until weaning, which occurred on PN25. After this time, rats were housed in same sex pairs of the same treatment condition except for those that had catheter implants. In this case, rats were housed singly after surgery. Food and water were available ad libitum except for rats tested in the food responding study. These rats were maintained on a food-restricted diet so that their body weights were at $85 \%$ of free-feeding rats. We employed no more than two rats per litter in each study as per our standard procedure (Kosten et al, 2004). All procedures were approved by the Institutional Animal Care and Use Committee and followed the NIH Guide for the Care and Use of Laboratory Animals.

Apparatus. Standard operant chambers (Coulbourn Instruments, Allentown, PA) were housed in ventilated, soundattenuating cubicles (Coulbourn Instruments) with fans to mask outside noise. On one wall of each chamber, there were two response levers and above each were three 'cue' lights, as described previously (Kosten et al, 2000, 2004). Minimal downward pressure (about $25 \mathrm{~g}$ ) on a lever could result in a programmed response. A recessed food receptacle into which food pellets $(45 \mathrm{mg}$ each; Bio-Serv Inc., Frenchtown, NJ) could be dispensed from a pellet dispenser that was located between the two levers. A house light was also located within the chamber. The chambers were equipped with syringe pump systems that consisted of an infusion pump (Razel model A, Stamford, CT) with a $20 \mathrm{ml}$ glass syringe connected by a single-channel 22-gauge swivel and clamp (Instech Laboratories, Plymouth Meeting, PA) with Teflon tubing. The tubing could be connected to the animal's catheter system in order to deliver drug solutions intravenously for the self-administration study. A software package (Graphic State Notation, Coulbourn) installed on a PC computer was used to program experimental parameters (schedules of reinforcements, time periods, etc). This system was used for both the selfadministration and food responding studies.

\section{Experiment 1. Maintenance of Cocaine Self-Administration Behavior}

Subjects. This study employed adult $(\geqslant \mathrm{PN} 90)$ female rats. The seven ISO rats were derived from five litters and the six $\mathrm{NH}$ rats were derived from five litters.

Surgery. Under ketamine $(10 \mathrm{mg} / \mathrm{kg})$ and xylazine $\mathrm{HCl}$ $(0.2 \mathrm{mg} / \mathrm{kg})$ anesthesia (i.p.), rats were implanted with chronically indwelling catheters, made of Silastic tubing, into the right jugular vein as described previously (Kosten et al, 2000, 2004). An incision was made on the back and catheters passed under the skin and were threaded out of the incision. The catheter was connected to a single-guide cannula (22 ga; Plastics One, Roanoke, VA) attached to a covance infusion harness (Instech Laboratories). Rats were treated with antibiotic during the first 3 days and allowed to recover for at least 4 days. Catheters were flushed approximately 5 days a week to maintain patency.

Drug. Cocaine hydrochloride was provided by the National Institute on Drug Abuse (Research Triangle Institute, Research Triangle Park, NC). Solutions were prepared fresh daily and were sterile filtered. Body weight was measured daily in order to determine dose individually by rat.

Training. Prior to surgery, rats were food-deprived to $85 \%$ of their free-feeding body weight. They were allowed to lever press for food pellets ( $45 \mathrm{mg}$; Bio-Serv Inc., Frenchtown, NJ) in the operant chambers under an FR1 schedule of reinforcement until at least 100 pellets were obtained within a $60 \mathrm{~min}$ session. Rats were returned to ad libitum food for at least 4 days prior to surgery.

Cocaine self-administration training sessions were conducted 5-7 days/week and were $3 \mathrm{~h}$ in length. The session began with two noncontingent intravenous drug infusion deliveries $(0.5 \mathrm{mg} / \mathrm{kg}$, delivered in $0.1 \mathrm{ml}$ over $10 \mathrm{~s})$. Initially, rats were allowed to lever press for a $0.5 \mathrm{mg} / \mathrm{kg} /$ infusion of cocaine under the FR1 schedule of reinforcement. An active lever depression led to a $100 \mu \mathrm{l}$ infusion of cocaine solution delivered over $10 \mathrm{~s}$ through the catheter. Inactive lever presses were tabulated but had no programmed consequences. At the session onset, the house light was 
illuminated and remained on until the active lever was pressed. This resulted in a cocaine infusion during which the cue lights over the active lever were illuminated and the house light was turned off. At the end of the infusion, all lights were turned off for a $5 \mathrm{~s}$ timeout period. Lever presses on the active lever emitted during the infusion and timeout periods did not result in cocaine delivery but were tabulated. The schedule was raised to FR2 and then FR3 after stable response rates were seen and training continued until acquisition occurred (standard deviation of the mean for 3 consecutive days was less than $20 \%$ of the mean).

Testing. Rats were tested under the FR3 schedule in $3 \mathrm{~h}$ sessions in which they were allowed to self-administer each of five doses $(0.0625,0.125,0.25,0.5$, and $1.0 \mathrm{mg} / \mathrm{kg} /$ infusion) on separate sessions. Doses were presented in a nonsystematic sequence. Tests were performed under a PR schedule in which the response requirement for each successive injection increased by progressive increments according to the following series: $1,2,4,6,9,12,15,20,25$, $32,40,50,62,77,95,118,145,178,219,268,328,402,492$, and 603 (Richardson and Roberts, 1996). Rats were allowed to self-administer either saline $(0 \mathrm{mg} / \mathrm{kg} /$ infusion $)$ or one of two cocaine doses ( 0.5 and $1.0 \mathrm{mg} / \mathrm{kg} /$ infusion) in $6 \mathrm{~h}$ sessions under this schedule on separation occasions. These tests were conducted in a nonsystematic sequence across rats. At least 2-3 days of self-administration training sessions intervened between tests to ensure that the animal had returned to its baseline response level.

Data analysis. Analyses of responding under the FR3 schedule included tabulating numbers of active and inactive lever presses for each dose. These dose response data were analyzed using a $2 \times 5$ ANOVA representing the betweengroup factor of Treatment condition (ISO vs $\mathrm{NH}$ ) with repeated measures on Dose. We calculated the amount of cocaine intake by multiplying numbers of self-administered infusions by the dose provided in the test session. Analyses of responding under the PR schedule included numbers of active lever presses emitted, numbers of earned reinforcers, and final ratio completed. The first two measures were analyzed using a $2 \times 3$ ANOVA representing the betweengroup factor of Treatment condition and repeated measures on Dose. The third measure, final ratio completed, was analyzed using the nonparametric Mann-Whitney $U$-test because these ratios were derived from an escalating exponential function, which violates the assumption of the homogeneity of variance for ANOVA (Richardson and Roberts, 1996). These data are presented as median whereas all other data are presented as mean \pm SEM. Post hoc comparisons between Treatment groups were used for simple effects at each cocaine dose. Significance levels were set at 0.05 .

\section{Experiment 2: Maintenance of Operant Responding for Food}

Subjects. Separate sets of adult $(\geqslant$ PN90) ISO $(n=8)$ and $\mathrm{NH}(n=12)$ female rats were employed in this study. Rats from the ISO condition were derived from seven litters and rats from the $\mathrm{NH}$ condition were derived from 10 litters.
Training. Rats were food restricted to $85 \%$ of free-feeding body weight relative to nondeprived rats of the same age. Initially, rats were allowed to press either lever for food pellets (45 mg; Bio-Serv) under an FR1 schedule of reinforcement. A total of 50 food pellets could be obtained during a session. Sessions began with the illumination of the house light and ended once 50 reinforcers were earned or 30 min elapsed, whichever occurred first. Then, the FR requirement was increased gradually until stable responding under an FR15 was achieved.

Testing. Once the rat showed consistent response rates (standard deviation of the mean for 3 consecutive days was less than $20 \%$ of the mean), test sessions were initiated. These sessions were conducted twice weekly (Tues. and Fri.) with training sessions conducted on intervening days (Mon., Wed., Thurs.). Tests were conducted under two PR schedules, a PR5 in which the response requirement increased by 5 after each earned reinforcer and the escalating PR schedule used in the cocaine self-administration study (Richardson and Roberts, 1996). These test sessions were $60 \mathrm{~min}$ in length and the total number of lever presses and earned food reinforcers were tabulated as well as final ratios completed. Test sessions were presented in a nonsystematic manner across rats.

Data analysis. Response rate (number of lever presses per second) data under the FR15 schedule as well as numbers of lever presses emitted and reinforcers earned under the PR schedules were compared across treatment conditions using $t$-tests and are presented as mean \pm SEM. Data on final ratios completed under the $\mathrm{PR}$ schedules were compared using the nonparametric statistic, Mann-Whitney $U$-test. These data are presented as medians. Significance levels were set at 0.05 .

\section{Results}

\section{Experiment 1. Maintenance of Cocaine Self-Administration Behavior}

Figure 1 presents data on numbers of active lever presses emitted under the FR3 schedule of reinforcement by cocaine dose. As seen in Figure 1, both ISO and NH female rats emit an increase and then a decrease in the numbers of active lever presses as cocaine dose increases, the characteristic inverted U-shaped dose effect function. This is supported by the significant Dose effect $(\mathrm{F}(4,44)=10.40, P<0.0001)$. ISO rats respond at higher rates than $\mathrm{NH}$ rats across cocaine doses, as supported by the significant Treatment condition effect $(\mathrm{F}(1,11)=5.68, \quad P<0.05)$ and by the significant Treatment $\times$ Dose interaction $(\mathrm{F}(4,44)=2.49, P<0.05)$. Post hoc analyses reveal a significant Treatment condition effect on active lever presses at the $0.125 \mathrm{mg} / \mathrm{kg} /$ infusion dose $(\mathrm{F}(1,11)=8.71, P<0.05)$. There are no significant effects on numbers of inactive lever presses emitted, which are minimal across doses ( $P$ 's $>0.10$; data not shown).

Figure 2 presents the total cocaine intake by dose. Intake increases with increasing cocaine doses as supported by the significant Dose effect $(\mathrm{F}(4,44)=64.08, P<0.0001)$. Intake is higher in ISO rats compared to $\mathrm{NH}$ rats. This statement is supported by the significant Treatment condition effect 


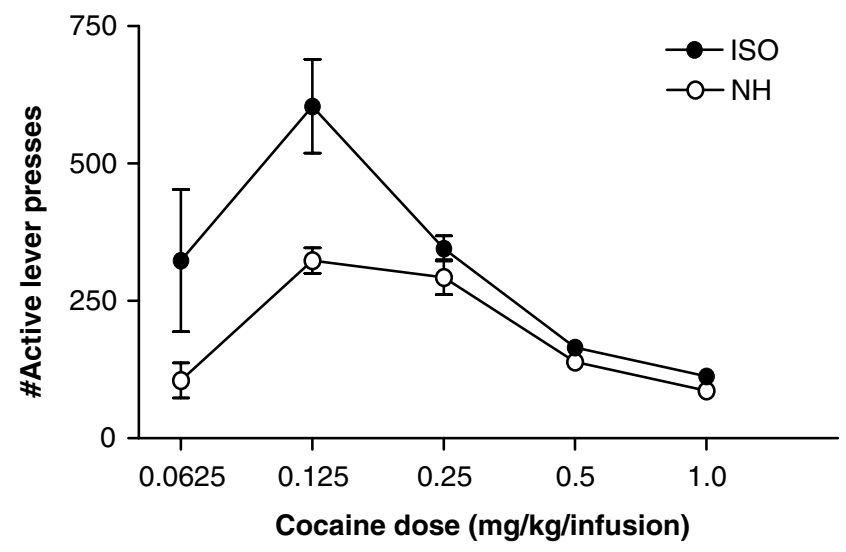

Figure I Mean \pm SEM numbers of active lever presses emitted by ISO (closed circles; $n=7$ ) and $\mathrm{NH}$ (open circles; $n=6$ ) female rats under the FR3 schedule are presented by cocaine dose ( $\mathrm{mg} / \mathrm{kg} /$ infusion). Neonatal isolation increases active lever responding. Post hoc analyses showed significant treatment condition differences at the $0.125 \mathrm{mg} / \mathrm{kg} /$ infusion dose $(P<0.05)$

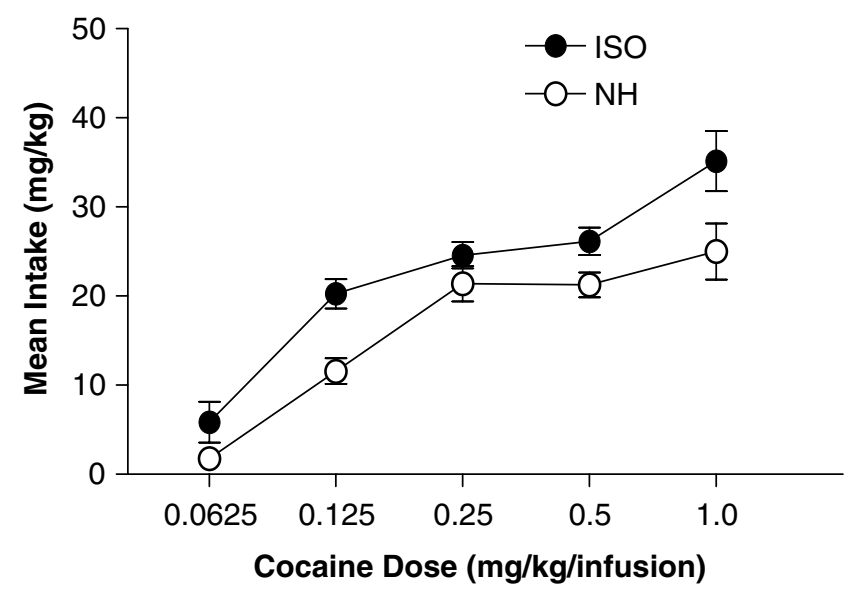

Figure 2 Mean $( \pm \mathrm{SEM})$ cocaine intake $(\mathrm{mg} / \mathrm{kg} / \mathrm{session})$ by dose are presented for ISO (closed circles; $n=7$ ) and $\mathrm{NH}$ (open circles; $n=6$ ) female rats. Intake increases as cocaine dose increases. Neonatal isolation increases cocaine intake. Post hoc analyses showed significant treatment condition differences at the 0.125 and $0.5 \mathrm{mg} / \mathrm{kg} /$ infusion doses ( $P$ 's $<0.05)$.

$(\mathrm{F}(1,11)=10.27, P<0.01)$. Post hoc analyses reveal significant Treatment conditions in active lever presses at the $0.125 \mathrm{mg} / \mathrm{kg} /$ infusion dose $(\mathrm{F}(1,11)=15.13, P<0.005)$ and at the $0.5 \mathrm{mg} / \mathrm{kg} /$ infusion dose $(\mathrm{F}(1,11)=5.38, P<0.05)$, and a trend toward significance at the $1.0 \mathrm{mg} / \mathrm{kg} /$ infusion dose $(\mathrm{F}(1,11)=4.71, P<0.06)$. The interaction of Treatment condition by Cocaine dose is not significant $(P>0.10)$.

Numbers of active lever presses emitted under the PR schedule are presented in Figure 3. Note that one $\mathrm{NH}$ rat was eliminated from the study before these tests were conducted due to catheter problems. Thus, data are from seven ISO and five NH female rats. As seen in Figure 3, numbers of active lever presses are low when saline was available and increase when cocaine was available. This is supported by the significant Dose effect $(F(2,15)=20.67$, $P<0.0001$ ). ISO female rats emit greater numbers of active lever presses than $\mathrm{NH}$ female rats, as supported by the significant Treatment condition effect $(\mathrm{F}(1,10)=10.23$,

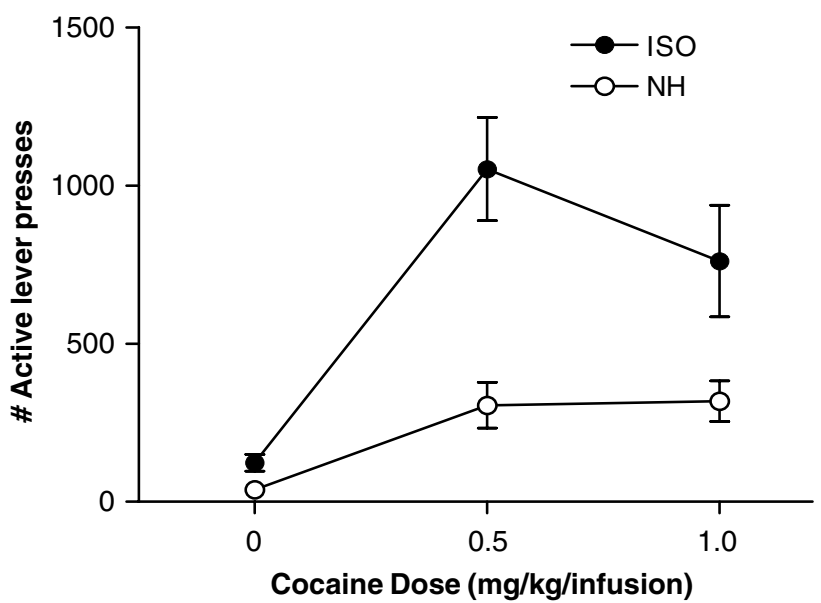

Figure 3 Mean ( \pm SEM) number of active lever presses emitted by ISO (closed circles; $n=7$ ) and $\mathrm{NH}$ (open circles; $n=5$ ) female rats under the PR schedule are presented by cocaine dose ( $\mathrm{mg} / \mathrm{kg} /$ infusion). Neonatal isolation increases active lever responding. Post hoc analyses showed significant treatment condition differences at the 0.5 and $1.0 \mathrm{mg} / \mathrm{kg} /$ infusion doses $(P<0.005)$

Table I Median Final Ratios Completed and Mean \pm SEM Reinforcers Earned Under the PR Cocaine Self-Administration Tests by Cocaine Dose for Isolated $(n=7)$ and Nonhandled $(n=5)$ Female Rats

\begin{tabular}{|c|c|c|c|c|}
\hline \multirow{2}{*}{$\begin{array}{l}\text { Cocaine } \\
\text { dose (mg/kg/ } \\
\text { infusion) }\end{array}$} & \multicolumn{2}{|c|}{ Final ratio completed ${ }^{\mathrm{a}}$} & \multicolumn{2}{|c|}{$\begin{array}{l}\text { Number of earned } \\
\text { reinforcers }^{\mathrm{a}}\end{array}$} \\
\hline & Isolated & Nonhandled & Isolated & Nonhandled \\
\hline 0 & 20 & 9 & $8.6 \pm 0.9$ & $5.4 \pm 1.2$ \\
\hline 0.5 & 178 & 50 & $17.9 \pm 0.9$ & $12.0 \pm 0.9$ \\
\hline 1.0 & 118 & 50 & $16.1 \pm 1.0$ & $12.6 \pm 0.6$ \\
\hline
\end{tabular}

${ }^{\mathrm{a}}$ Represents significant treatment effect.

$P<0.01)$ and by the significant Treatment $\times$ Dose interaction $(\mathrm{F}(2,15)=5.80, P<0.01)$. Post hoc analyses reveal significant Treatment effects for the $0.5 \mathrm{mg} / \mathrm{kg} /$ infusion dose $(\mathrm{F}(1,10)=6.10, \quad P<0.05)$ and for the $1.0 \mathrm{mg} / \mathrm{kg} /$ infusion dose $(\mathrm{F}(1,10)=13.25, P<0.005)$. The numbers of earned reinforcers and final ratios completed are presented in Table 1. As seen in Table 1, numbers of earned reinforcers are low when saline is available and increase when cocaine is available. This statement is supported by the significant Dose effect $(\mathrm{F}(2,15)=89.49, P<0.0001)$. ISO female rats obtain more reinforcers than $\mathrm{NH}$ female rats, as supported by the significant Treatment condition effect $(\mathrm{F}(1,10)=13.18, P<0.005)$. Post hoc analyses reveal significant Treatment effects for the $0.5 \mathrm{mg} / \mathrm{kg} /$ infusion dose $(\mathrm{F}(1,10)=18.92, P<0.005)$ and for the $1.0 \mathrm{mg} / \mathrm{kg} /$ infusion dose $(\mathrm{F}(1,10)=7.02, P<0.05)$. The interaction of Treatment condition by Cocaine dose is not significant for this measure $(P>0.10)$. Final ratios completed are greater when cocaine is available $v s$ when saline is available $(P<0.05)$ as seen in Table 2 and are higher in ISO vs $\mathrm{NH}$ female rats $(P<0.05)$. 
Table 2 Mean \pm SEM Total Numbers of Lever Presses Emitted and Reinforcers Earned and Median of the Final Ratio Completed in the Two PR Tests of Food Responding for Isolated $(n=8)$ and Nonhandled Female Rats $(n=12)$

\begin{tabular}{lccccc}
\hline & \multicolumn{2}{c}{ PR-5 schedule } & \multicolumn{2}{c}{ Escalating PR schedule ${ }^{\mathbf{a}}$} \\
\cline { 2 - 3 } \cline { 5 - 6 } Measure & Isolated & Nonhandled & Isolated & Nonhandled \\
\hline $\begin{array}{l}\text { Total lever } \\
\text { presses }\end{array}$ & $874.3 \pm 107.8$ & $760.6 \pm 84.8$ & $717.2 .0 \pm 126.3$ & $440.3 \pm 33.9$ \\
$\begin{array}{l}\text { Total reinforcers } \\
\text { earned }\end{array}$ & $17.2 \pm 1.2$ & $16.0 \pm 0.9$ & $16.3 \pm 0.7$ & $14.4 \pm 0.3$ \\
$\begin{array}{l}\text { Final ratio } \\
\text { completed }\end{array}$ & 92.5 & 80 & 118 & 77 \\
\hline
\end{tabular}

${ }^{\text {a }}$ Represents significant treatment effect.

\section{Experiment 2: Maintenance of Operant Responding for Food}

Immediately prior to food restriction, ISO and $\mathrm{NH}$ females did not differ in body weight (ISO: $344 \pm 30 \mathrm{~g}$; NH: $382 \pm 21 \mathrm{~g} ; P>0.10$ ). Under the FR15 schedule of reinforcement, there is no difference in response rates (lever presses per second) between ISO and NH female rats $(P>0.10)$. The mean $( \pm$ SEM $)$ rate for ISO rats is $1.05( \pm 0.13)$ and for $\mathrm{NH}$ rats is $0.96( \pm 0.12)$ presses per second. ISO rats emit greater numbers of lever presses under the escalating PR schedule as seen in Table 2. This statement is supported by the significant Treatment condition effect $(t(18)=2.87$, $P<0.01)$. Further, numbers of reinforcers earned are greater in ISO $v s \mathrm{NH}$ female rats as seen in Table $2(t(18)=3.38$, $P<0.005)$. There are no significant Treatment effects seen under the PR5 schedule as seen in Table $2(P$ 's $>0.10)$. There are no significant Treatment effects on final ratios completed for either schedule $\left(P^{\prime}\right.$ 's $\left.>0.10\right)$.

\section{DISCUSSION}

The results of the present study show that neonatal isolation (ISO) enhances cocaine and food self-administration in adult female rats after behavior is well established. Responding for cocaine is increased by ISO under both FR and PR schedules. We have also shown that when cocaine dose is held constant and the FR is altered, cocaine intake remains stable but greater in ISO $v s \mathrm{NH}$ female rats (Kosten et al, 2004). Further, that ISO also enhances responding for food under the escalating PR schedule, the same schedule used in the cocaine self-administration study, does not support a specific effect of ISO on increased sensitivity to cocaine. Thus, ISO appears to have a more general effect on reward-related operant performance in female rats, facilitating the acquisition (Kosten et al, 2004) and maintenance (present study) of responding for cocaine and food.

Female rats with ISO experience exhibit heightened responding for cocaine and increased cocaine intake relative to $\mathrm{NH}$ female rats. This effect is particularly strong at the dose where peak responding is seen $(0.125 \mathrm{mg} / \mathrm{kg} /$ infusion) under the FR schedule of reinforcement. But, increased intake in ISO rats also occurs at high cocaine doses (eg $0.5 \mathrm{mg} / \mathrm{kg} /$ infusion) under both $\mathrm{FR}$ and $\mathrm{PR}$ schedules. Similar results are reported for female rats with prolonged maternal separation experience compared to those with brief handling experience (Matthews et al, 1999). Because ISO enhances responding across a wide cocaine dose range under the FR schedule in addition to enhancing responding under the PR schedule, it is unlikely that this reflects an ISO-induced alteration in the sensitivity to cocaine. Rather, ISO appears to enhance the motivation to obtain cocaine as well as food in female rats.

ISO improves acquisition of food responding in female rats (Kosten et al, 2004). In the present study, in which the rats are well trained, enhanced responding for food is seen under a PR schedule in ISO $v s \mathrm{NH}$ female rats, whereas no differences in response rates occur under an FR schedule. Responding under PR schedules is thought to reflect the degree of work the animal will perform to obtain reinforcer delivery (Hodos, 1961; Rodefer and Carroll, 1996). Thus, ISO enhances the amount of work that female rats will perform to obtain either food or cocaine. Previous studies have linked this type of behavior to accumbens DA (Robbins and Everitt, 1992; Salamone et al, 2003) and we have shown this to be altered by ISO (Kehoe et al, 1996, 1998a; Kosten et al, 2003).

The rats in the present study ingested large amounts of cocaine over the course of training. It is possible that the increase in responding for cocaine in ISO female rats reflects a greater degree of sensitization to the effects of cocaine. However, female rats with maternal separation experience (either 15 or $180 \mathrm{~min}$ of whole litter separation from the dam per day on PN1-21) exhibit significantly less cocaine locomotor sensitization than control rats ( $\mathrm{Li}$ et al, 2003). Another study reports no effect of $4 \mathrm{~h}$ repeated maternal separation on the expression of amphetamine locomotor sensitization in adult female rats (Weiss et al, 2001). Although these studies utilized whole litter separation in which the pup is huddled with littermates and exposed to tactile, olfactory, and other familiar sensory cues as opposed to the individual pup isolation used in the present study, this suggests that it is unlikely that ISO enhances sensitization to cocaine. Indeed, it is difficult to explain both an ISO-induced increase in cocaine selfadministration and an increase in food self-administration by alterations in cocaine sensitization because the latter effect is seen in rats with no prior cocaine exposure. Further, ISO facilitates acquisition of cocaine self-administration in female rats by improving response learning. In fact, during acquisition, ISO rats actually self-administer less cocaine than control, $\mathrm{NH}$ female rats (Kosten et al, 2004). The large cocaine intake we observed in NH female rats relative to male rats is similar to findings of sex differences in acquisition of cocaine self-administration reported in previous studies (Lynch and Carroll, 1999; $\mathrm{Hu}$ et al, 2004). NH female rats show poor lever discrimination and thus acquire the cocaine self-administration operant less rapidly than ISO female rats or male rats. Moreover, the less rapid acquisition of cocaine self-administration we find in female $v s$ male $\mathrm{NH}$ rats is consistent with a recent study on sex differences in acquisition of cocaine self-administration (Caine et al, 2004).

The possibility that ISO may increase response rates due to nonspecific enhancements in activity levels is unlikely. 
We have consistently shown that baseline activity levels do not differ between ISO and NH rats (Kehoe et al, 1996, 1998b; Kosten et al, 2000, 2004, 2005a). There are also no group differences in inactive lever press responses in the self-administration study and no differences in baseline response rates in the food study. It is also unlikely that ISO could have altered cocaine metabolism (Kosten et al, 2005b). Further, as seen in the present study and in our previous work, ISO does not alter body weight. A potential confounding factor in the present study is the estrous cycle stage. The estrous cycle of mature female rats lasts about 4 days during which levels of circulating gonadal hormone levels fluctuate. Estrous stage affects cocaine-induced locomotor activity (Quinones-Jenab et al, 1999; Sell et al, 2000) as well as responding for cocaine under a PR schedule (Roberts et al, 1989). Yet, estrous stage does not affect responding for cocaine under an FR schedule of reinforcement (Roberts et al, 1989). Because tests were conducted about every 3 days in the present study, it is likely that individual rats were tested during various phases and any effect of estrous stage would have been similar across dose tests and groups. Although estrous cyclicity does not differ between ISO and NH female rats (Kosten et al, 2005b), we cannot rule out the possibility that some effect of estrous stage contributed to the results seen in the present study. However, it should be noted that the self-administration data show very little variability (see Figures 1-3).

Enhanced responding for cocaine and food in ISO female rats may reflect, in part, alterations in the ventral striatal DA system. This system plays an important role in the behavioral effects of cocaine, in responding for food, and in stress (see Introduction). Our previous in vivo microdialysis studies show that ISO enhances ventral striatal DA levels in response to acute psychostimulant administration in infant and juvenile rats although there are no differences in baseline levels relative to $\mathrm{NH}$ control rats (Kehoe et al, 1996, 1998a; Kosten et al, 2003). The early life stress of maternal separation also enhances extracellular ventral striatal DA levels in response to acute amphetamine in adult rats (Hall et al, 1999). However, it is likely that alterations in other neural or hormonal systems also contribute to the behavioral effects reported on in the present study.

The results of the cocaine self-administration study along with our previous work demonstrating enduring effects of neonatal isolation in female rats point to the possibility that women with early life stress experience may be at increased risk of initiating and maintaining drug addiction. Further, early life stress may also enhance other appetitive behaviors in women based on our finding that ISO enhances responding for food under a condition thought to reflect motivation to work for reinforcement. Indeed, that ISO enhances responding for food in female rats, but not male rats (Kosten et al, 2000, 2004; Zhang et al, 2005), may provide an insight into the role of early life stress on gender differences in vulnerability to develop eating disorders (Seeman, 1997).

\section{ACKNOWLEDGEMENTS}

This research was supported by the Patrick and Catherine Weldon Donaghue Foundation (DF \# 00-202) and by the
Yale IWHR Scholar Program on Women and Drug Abuse (1K12DA14038). We gratefully acknowledge the technical assistance provided by Hayde Sanchez, Joanne Lee, and Diane Lendroth.

\section{REFERENCES}

Becker JB (1999). Gender differences in dopaminergic function in striatum and nucleus accumbens. Pharmacol Biochem Behav 64: 803-812.

Bell SM, Stewart RB, Thompson SC, Meisch RA (1997). Food deprivation increases cocaine-induced conditioned place preference and locomotor activity in rats. Pscyhopharmacology 131: $1-8$.

Bergman J, Madras BK, Johnson SE, Spealman RD (1989). Effects of cocaine and related drugs in nonhuman primates III: selfadministration by squirrel monkeys. J Pharmacol Exp Ther 251: 150-155.

Caine SB, Bowen CA, Yu G, Zuzga D, Negus SS, Mello NK (2004). Effect of gonadectomy and gonadal hormone replacement on cocaine self-administration in female and male rats. Neuropsychopharmacology 29: 929-942.

Deminiere JM, Piazza PV, Guegan G, Abrous N, Maccari S, Moal ML et al (1992). Increased locomotor response to novelty and propensity to intravenous amphetamine self-administration in adult offspring of stressed mothers. Brain Res 586: 135-139.

Deroche V, Marinelli M, Maccari S, LeMoal M, Simon H, Piazza PV (1995). Stress-induced sensitization and glucocortiocids. I. Sensitization of dopamine-dependent locomotor effects of amphetamine and morphine depends on stress-induced corticosterone secretion. J Neurosci 15: 7181-7188.

Deutch AY, Roth RH (1990). The determinants of stress-induced activation of the prefrontal cortical dopamine system. Prog Brain Res 85: 357-393.

Fadda F, Argiolas A, Melis MR, Tissari AH, Onali PL, Gessa GL (1978). Stress-induced increase in 3,4-dihydroxyphenylacetic acid (DOPAC) levels in the cerebral cortex and in the nucleus accumbens: reversal by diazepam. Life Sci 23: 2219-2224.

Haile CN, Grandpre TN, Kosten TA (2001). Chronic unpredictable stress, but not chronic predictable stress, enhances the sensitivity to the behavioral effects of cocaine. Psychopharmacology 154: 213-220.

Hall FS, Wilkinson LS, Humby T, Robbins TW (1999). Maternal deprivation of neonatal rats produces enduring changes in dopamine function. Synapse 32: 37-43.

Hamamura T, Fibiger HC (1993). Enhanced stress-induced dopamine release in the prefrontal cortex of amphetaminesensitized rats. Eur J Pharmacol 237: 65-71.

Haney M, Maccari S, LeMoal M, Simon H, Piazza PV (1995). Social stress increases the acquisition of cocaine self-administration in male and female rats. Brain Res 698: 46-52.

Herman JP, Stinus L, LeMoal M (1984). Repeated stress increases locomotor response to amphetamine. Psychopharmacology 84: 431-435.

Hodos W (1961). Progressive ratio as a measure of reward. Science 134: 943-944.

$\mathrm{Hu}$ M, Crombag HS, Robinson TE, Becker JB (2004). Biological basis of sex differences in the propensity to self-administer cocaine. Neuropsychopharmacology 29: 81-85.

Imperato A, Angelucci L, Casolini P, Zocchi A, Puglisi-Allegra S (1992). Repeated stressful experiences differently affect limbic dopamine release during and following stress. Brain Res 577: 194-199.

Kehoe P, Shoemaker WJ, Arons C, Triano L, Suresh G (1998a). Repeated isolation stress in the neonatal rat: relation to brain dopamine systems in the 10-day-old rat. Behav Neurosci 112: 1466-1474. 
Kehoe P, Shoemaker WJ, Triano L, Callahan M, Rappolt G (1998b). Adult rats stressed as neonates show exaggerated behavioral responses to both pharmacological and environmental challenges. Behav Neurosci 112: 116-125.

Kehoe P, Shoemaker WJ, Triano L, Hoffman J, Arons C (1996). Repeated isolation in the neonatal rat produces alterations in behavior and ventral striatal dopamine release in the juvenile following amphetamine challenge. Behav Neurosci 110: 1434-1444.

Knich ET, Eisenberg RM (1979). Effect of amphetamine on plasma corticosterone in the conscious rat. Neuroendocrinology 29: $110-118$.

Koob GF, Bloom FE (1988). Cellular and molecular mechanisms of drug dependence. Science 242: 715-723.

Kosten TA, Miserendino MJD, Bombace JC, Lee HJ, Kim JJ (2005a). Sex-selective effects of neonatal isolation on fear conditioning and foot shock sensitivity. Behav Brain Res 157: 235-244.

Kosten TA, Miserendino MJD, Kehoe P (2000). Enhanced acquisition of cocaine self-administration in adult rats with neonatal isolation stress experience. Brain Res 875: 44-50.

Kosten TA, Sanchez H, Jatlow PI, Kehoe P (2005b). Neonatal isolation alters estrous cycle interaction on acute behavioral effects of cocaine. Psychoneuroendocrinology 30: 753-761.

Kosten TA, Sanchez H, Zhang XY, Kehoe P (2004). Neonatal isolation enhances acquisition of cocaine self-administration and food responding in female rats. Behav Brain Res 151: 137-149.

Kosten TA, Zhang XY, Kehoe P (2003). Chronic neonatal isolation stress enhances cocaine-induced increases in ventral striatal dopamine levels in rat pups. Brain Res Dev Brain Res 141: 109-116.

Kosten TR, Rounsaville BJ, Kleber HD (1986). A 2.5-year follow-up of depression, life crises, and treatment effects on abstinence among opioid addicts. Arch Gen Psychiatry 43: 733-738.

Leyton M, Stewart J (1990). Preexposure to foot-shock sensitizes the locomotor response to subsequent systemic morphine and intra-accumbens amphetamine. Pharmacol Biochem Behav 37: 303-310.

Li YL, Robinson TE, Bhatnagar S (2003). Effects of maternal separation on behavioural sensitization produced by repeated cocaine administration in adulthood. Brain Res 960: 42-47.

Lynch W, Carroll ME (1999). Sex differences in the acquisition of intravenously self-administered cocaine and heroin in rats. Psychopharmacology 144: 77-82.

Matthews K, Robbins TW, Everitt BJ, Caine SB (1999). Repeated neonatal maternal separation alters intravenous cocaine selfadministration in adult rats. Psychopharmacology 141: 123-134.

Moldow RL, Fischman AJ (1987). Cocaine induced secretion of ACTH, beta-endorphin and corticosterone. Peptides 8: 819-822.

Najavits LM, Gastfriend DR, Barber JP, Reif S, Muenz LR, Blaine J et al (1998). Cocaine dependence with and without PTSD among subjects in the National Institute on Drug Abuse Collaborative Cocaine Treatment Study. Am J Psychiatry 155: 214-219.

Piazza PV, Deminiere J-M, LeMoal M, Simon H (1990). Stress- and pharmacologically-induced behavioral sensitization increases vulnerability to acquisition of amphetamine self-administration. Brain Res 514: 22-26.

Quinones-Jenab V, Ho A, Schlussman SD, Franck J, Kreek MJ (1999). Estrous cycle differences in cocaine-induced stereotypic and locomotor behaviors in Fischer rats. Behav Brain Res 101: $15-20$.

Rhoads DL (1983). A longitudinal study of life stress and social support among drug abusers. Int J Addict 18: 195-222.
Richardson NR, Roberts DC (1996). Progressive ratio schedules in drug self-administration studies in rats: a method to evaluate reinforcing efficacy. J Neurosci Methods 66: 1-11.

Ritz MC, Lamb RJ, Goldberg SR, Kuhar MJ (1987). Cocaine receptors on dopamine transporters are related to self-administration of cocaine. Science 237: 1219-1223.

Rivier C (1999). Gender, sex steroids, corticotropin-releasing factor, nitric oxide, and the HPA response to stress. Pharmacol Biochem Behav 64: 739-751.

Rivier CL, Vale W (1987). Cocaine stimulates adrenocorticotropin (ACTH) secretion through a corticotropin-releasing (CRF)mediated mechanism. Brain Res 422: 403-406.

Robbins TW, Everitt B (1992). Functions of dopamine in dorsal and ventral striatum. Neuroscience 4: 119-127.

Roberts DCS, Bennett SAL, Vickers GJ (1989). The estrous cycle affects cocaine self-administration on a progressive ratio schedule in rats. Psychopharmacology 98: 408-411.

Rodefer JS, Carroll ME (1996). Progressive ratio and behavioral economic evaluation of the reinforcing efficacy of orally delivered phencyclidine and ethanol in monkeys: effects of feeding conditions. Psychopharmacology 128: 265-273.

Saal D, Dong Y, Bonci A, Malenka RC (2003). Drugs of abuse and stress trigger a common synaptic adaptation in dopamine neurons. Neuron 37: 577-582.

Salamone JD, Correa M, Mingote S, Weber SM (2003). Nucleus accumbens dopamine and the regulation of effort in foodseeking behavior: implications for studies of natural motivation, psychiatry, and drug abuse. J Pharmacol Exp Ther 305: 1-8.

Seeman MV (1997). Psychopathology in women and men: focus on female hormones. Am J Psychiatry 154: 1641-1647.

Sell SL, Scalzitti JM, Thomas ML, Cunningham KA (2000). Influence of ovarian hormones and estrous cycle on the behavioral response to cocaine in female rats. J Pharmacol Exp Ther 293: 879-886.

Shaham Y, Stewart J (1994). Exposure to mild stress enhances the reinforcing efficacy of intravenous heroin in rats. Psychopharmacology 114: 523-527.

Sorg BA, Kalivas PW (1991). Effects of cocaine and footshock stress on extracellular dopamine levels in the ventral striatum. Brain Res 559: 29-36.

Tidey JW, Miczek KA (1997). Acquisition of cocaine selfadministration after social stress: role of accumbens dopamine. Psychopharmacology 130: 203-212.

Wechsberg WM, Craddock SG, Hubbard RL (1998). How are women who enter substance abuse treatment different than men? A gender comparison from the Drug Abuse Treatment Outcome Study (DATOS). Drugs Soc 13: 97-115.

Weiss IC, Domeney AM, Heidbreder CA, Moreau JL, Feldon J (2001). Early social isolation, but not maternal separation, affects behavioral sensitization to amphetamine in male and female adult rats. Pharmacol Biochem Behav 70: 397-409.

Will MJ, Watkins LR, Maier SF (1998). Uncontrollable stress potentiates morphine's rewarding properties. Pharmacol Biochem Behav 60: 655-664.

Wilsnack SC, Vogeltanz ND, Klassen AD, Harris TR (1997). Childhood sexual abuse and women's substance abuse: national survey findings. J Stud Alcohol 58: 264-271.

Zhang XY, Sanchez H, Kehoe P, Kosten TA (2005). Neonatal isolation enhances maintenance but not reinstatement of cocaine self-administration in adult male rats. Psychopharmacology 177: 391-399. 